\title{
Diagnóstico Histopatológico e Imuno-histoquímico de Linfoma de Baço com Apresentação Clínica Atípica: Relato de Caso
}

\author{
doi: https://doi.org/10.32635/2176-9745.RBC.2021v67n4.1432
}

\author{
Histopathological and Immunohistochemical Diagnosis of Spleen Lymphoma with Atypical Clinic Presentation: Case Report \\ Diagnóstico Histopatológico e Inmunohistoquímico de Linfoma de Bazo con Presentación Clínica Atípica: Relato de Caso
}

Gabrielle Ruthes Fragoso'; Eduardo Pires dos Santos²; Camila Moraes Marques³ Renata Bernardini de Lima ${ }^{4}$

RESUMO

Introduçáo: Tanto o angiossarcoma esplênico quanto o linfoma não Hodgkin (LNH) de células B não só são raros como apresentam desafios diagnósticos. Relato do caso: Paciente do sexo masculino, 45 anos, obeso, sudorese noturna há um ano, e dor abdominal cíclica há dois, com clínica inicial de angiossarcoma, contudo, sob o exame histopatológico e imuno-histoquímico, mostrou tratar-se de LNH de células B com apresentaçáo atípica. A ultrassonografia (US) de abdome total realizada ao início do sintoma de sudorese noturna não teve alteraçôes. Após um ano, a US apresentou massa esplênica. Na ressonância magnética da região abdominal, constatou-se tumoração esplênica expansiva heterogênea no aspecto anterior, suspeita de angiossarcoma esplênico. Após esplenectomia total, pancreatectomia caudal e linfadenectomia retroperitoneal, o exame histopatológico mostrou neoplasia maligna pouco diferenciada extensamente necrótica substituindo o parênquima esplênico. O estudo imuno-histoquímico foi positivo para os marcadores CD20 em diversos focos, para o BCL2 e para o KI67 (em 95\% dos núcleos das células neoplásicas). A histopatologia e a imuno-histoquímica foram compatíveis com o diagnóstico de LNH difuso de alto grau, com imunofenótipo B do baço, sem sinal de infiltração de tecidos adjacentes. Após a esplenectomia total e quatro ciclos de quimioterapia, o paciente estava livre do linfoma e sem sintomas. Conclusáo: É de suma importância o reconhecimento do diagnóstico correto de neoplasias raras como a relatada. Tanto a clínica quanto os exames de imagem, mesmo que fundamentais, podem ser imprecisos, reiterando a importância dos exames histológico e imuno-histoquímico complementares.

Palavras-chave: Neoplasias Esplênicas/diagnóstico; Linfoma não Hodgkin/diagnóstico; Relatos de Casos.

\section{ABSTRACT}

Introduction: Both the splenic angiosarcoma and the B-cell non-Hodgkin's lymphoma (NHL) are not only rare but are challenging to diagnose. Case report: Male patient, 45 years old, obese, night sweats for one year, and cyclic abdominal pain for two years, with an initial angiosarcoma clinic, however after immunohistochemistry test, it was revealed a B-cell NHL with atypical presentation. The total abdomen ultrasound (US) performed at the onset of the night sweating symptom showed no alterations. After one year, the US showed a splenic mass. Magnetic resonance imaging of the abdominal region revealed a heterogeneous expansive splenic lesion in the anterior aspect with suspected splenic angiosarcoma. After full splenectomy, caudal pancreatectomy, and retroperitoneal lymphadenectomy, histological analysis showed an area of poorly differentiated necrotic malignancy infiltrated in the splenic parenchyma. Immunohistochemical analysis was positive for CD20 reagents in several foci, BCL2, and for KI67 (in ninety percent of the neoplastic cell nucleus). Histopathology and immunohistochemistry are consistent with high-grade, diffuse, NHL of immunophenotype B in the spleen, with no sign of metastasis to adjacent tissues. After total splenectomy and four rounds of chemotherapy, the patient had remission of the tumor and was asymptomatic. Conclusion: It is extremely important to recognize the relevance of the correct diagnosis of rare neoplasms such as the one reported. Both clinical and imaging tests, although important, can be inaccurate, reiterating the importance of complementary histologic and immunohistochemical tests.

Key words: Splenic Neoplasms/diagnosis; Lymphoma, Non-Hodgkin/ diagnosis; Case Reports.

\section{RESUMEN}

Introducción: El angiosarcoma esplénico e el linfoma no Hodgkin (LNH) de células $\mathrm{B}$ no solo son raros sino que presentan un reto diagnóstico. Relato del caso: Paciente masculino de 45 años, obeso, con sudoración nocturna durante un año y dolor abdominal cíclico durante dos ańos, con clínica inicial de angiosarcoma, pero bajo inmunohistoquímica mostró LNH de células B con presentación atípica. En la ecografía de abdomen total realizada al comienzo del síntoma de sudoración nocturna no hubo cambios. Después de un año, la ecografía enseñó una masa esplénica. La resonancia magnética de la región abdominal reveló una lesión esplénica expansiva heterogénea en la cara anterior, sospechosa de angiosarcoma esplénico. Tras la esplenectomía total, la pancreatectomía caudal y la linfadenectomía retroperitoneal, el análisis histológico mostró un área de neoplasia maligna necrótica poco diferenciada infiltrada en el parénquima esplénico. El análisis inmunohistoquímico fue positivo para los reactivos CD20 en varios focos, BCL2 y KI67 en el 95\% del núcleo celular, la histología y la inmunohistoquímica son consistentes con LNH difuso de alto grado de inmunofenotipo B en el bazo, sin signos de metástasis. Tras esplenectomía total y cuatro rondas de quimioterapia, el paciente presentó remisión del tumor, así como disminución de síntomas. Conclusión: Es de suma importancia reconocer el diagnóstico de neoplasias raras como la reportada. Tanto las pruebas clínicas como las de imagen, aunque fundamentales, pueden ser inexactas, reiterando la importancia de las pruebas histopatológicas e inmunohistológicas.

Palabras clave: Neoplasias del Bazo/diagnóstico; Linfoma no Hodgkin/ diagnóstico; Informes de Casos.

1-3Faculdades Pequeno Príncipe (FPP). Curitiba (PR), Brasil. E-mails: gabiruthesfragoso@gmail.com; eduardo23.ps@outlook.com; camilam14@gmail.com. Orcid iD: https://orcid.org/0000-0002-7965-9988; Orcid iD: https://orcid.org/0000-0003-2336-1338; Orcid iD: https://orcid.org/0000-0001-5121-922X ${ }^{4}$ Hospital Erasto Gartner (HEG). Curitiba (PR), Brasil. E-mail: renabl@gmail.com. Orcid iD: https://orcid.org/0000-0001-7484-9259

Endereço para correspondência: Gabrielle Ruthes Fragoso. Avenida Iguaçu, 333 - Rebouças. Curitiba (PR), Brasil. CEP 80230-020. E-mail: gabiruthesfragoso@gmail.com 


\section{INTRODUÇÃO}

Os tumores primários do baço são extremamente raros. $\mathrm{O}$ angiossarcoma corresponde a menos de $1 \%$ dos sarcomas de tecidos moles e somente a minoria do total de casos surge no baço. Esses tumores frequentemente apresentam-se como um desafio diagnóstico para o patologista, tendo em vista as variaçóes na histopatologia. Por outro lado, o desenvolvimento de novos marcadores em painéis de imuno-histoquímica, como o CD31, é de grande valia para o descarte de outros diagnósticos diferenciais. $\mathrm{O}$ angiossarcoma esplênico primário está associado a um prognóstico muito ruim em virtude da sua dificuldade em diagnóstico e do seu alto potencial metastático ${ }^{1,2}$. Enquanto isso, os linfomas de Hodgkin (LH) acometem predominantemente linfonodos, baço e medula óssea, enquanto os linfomas não Hodgkin (LNH) podem apresentar manifestaçóes extranodais em aproximadamente $25 \%$ dos casos, mais comumente no estômago, pele, cavidade oral, intestino delgado e sistema nervoso central ${ }^{3}$. Os principais sinais e sintomas dos linfomas, em geral, incluem presença de massas tumorais, além de fadiga e prurido cutâneo; já os sintomas típicos de $\mathrm{LNH}$, fenótipo B, são febre, emagrecimento de mais de $10 \%$ do peso em seis meses, além de sudorese noturna.

O diagnóstico dos LNH se baseia na biópsia do linfonodo ou da massa tumoral extranodal, devendo o material ser examinado por patologista experiente que irá classificar a doença de acordo com critérios morfológicos e imuno-histoquímicos ${ }^{3}$.

O objetivo deste trabalho é relatar o caso de um paciente com clínica inicial de angiossarcoma, contudo, o diagnóstico histopatológico e imuno-histoquímico complementar mostrou tratar-se de LNH com imunofenótipo B e com apresentação atípica.

O Projeto foi aprovado pelo Comitê de Ética em Pesquisa da Faculdades Pequeno Príncipe, sob o número de parecer 4.163.551.

\section{RELATO DO CASO}

Paciente do sexo masculino, 45 anos, obeso (IMC $30,45)$, portador de hipertensão arterial sistêmica, hipotireoidismo (em tratamento) e pré-diabetes. Há histórico de hepatite $\mathrm{C}$, com tratamento completo, três meses antes do início dos sintomas. Nega cirurgias prévias. Ex-tabagista, etilista moderado. Possui parentes de segundo grau com história de câncer abdominal. Trabalha com produtos químicos há seis meses, contudo, relata fazer uso de equipamento de proteção individual (EPI).
Paciente referia sudorese noturna intensa há um ano, dor abdominal em hipocôndrio esquerdo com dois anos de evolução, que ocorria de forma cíclica. $\mathrm{Na}$ última crise, a dor retornou com maior intensidade. Nega febre e perda ponderal. Ao exame físico, notou-se baço palpável à inspiração profunda, sem outros achados dignos de nota.

A ultrassonografia de abdome total realizada ao início do sintoma de sudorese noturna não evidenciou alteraçôes. Após um ano, repetiu-se o exame, que mostrou massa esplênica. Na ressonância magnética da regiâo abdominal, foi constatada tumoração esplênica expansiva, heterogênea no aspecto anterior, medindo 136 × 123 × $88 \mathrm{~mm}$. Foram observados linfonodos com dimensôes aumentadas em regiâo porto-caval e no hilo hepático, medindo até 27 $\mathrm{mm}$, além de linfonodos proeminentes no retroperitônio em região porto-caval e periaórtica, medindo até $12 \mathrm{~mm}$. Embora não tenha sido possível determinar a natureza da tumoração do baço, houve suspeita de angiossarcoma esplênico.

O paciente foi submetido à esplenectomia total, à pancreatectomia caudal eà linfadenectomia retroperitoneal, com objetivo de retirar o tumor e classificá-lo. Foi efetuada incisão subcostal esquerda com $20 \mathrm{~cm}$. Foi encontrada volumosa tumoração comprometendo o baço. Constatou-se, ainda, ausência de disseminação peritoneal ou hepática. Já na parede abdominal, suspeitou-se de possível infiltração, que não foi confirmada nos exames histopatológicos.

O produto da esplenectomia pesava 1.292 gramas e media 17 × 15 x $10 \mathrm{~cm}$. Apresentava superfície externa vermelha vinhosa, com aspecto lobulado, parcialmente revestida por tecido adiposo. Aos cortes, constatou-se presença de tumoração esbranquiçada, lobulada, medindo $15 \times 14 \times 10 \mathrm{~cm}$, substituindo totalmente o órgão.

O exame histopatológico mostrou neoplasia maligna pouco diferenciada extensamente necrótica substituindo o parênquima esplênico (Figura 1). As margens cirúrgicas se mostraram livres de neoplasias, assim como os 12 linfonodos do hilo esplênico com aspecto histopatológico preservado.

O estudo imuno-histoquímico mostrou positividade para os marcadores CD20 (Figura 2) em diversos focos, para o BCL2 (Figura 3) e para o KI67 (Figura 4), em cerca de $95 \%$ dos núcleos das células neoplásicas. Houve negatividade para o CD3 e o CD30.

O quadro histopatológico e imuno-histoquímico foi condizente com o diagnóstico de LNH difuso de alto grau, com imunofenótipo B, substituindo completamente o baço, sem sinal de doença neoplásica nas regiôes adjacentes.

Após a esplenectomia total seguida por quatro ciclos de quimioterapia com R-CHOP (rifampicina, ciclofosfamida, hidroxidoxorubicina, vincristina e 
prednisona), o paciente apresentou-se livre de tumor, assim como desapareceram os sintomas.

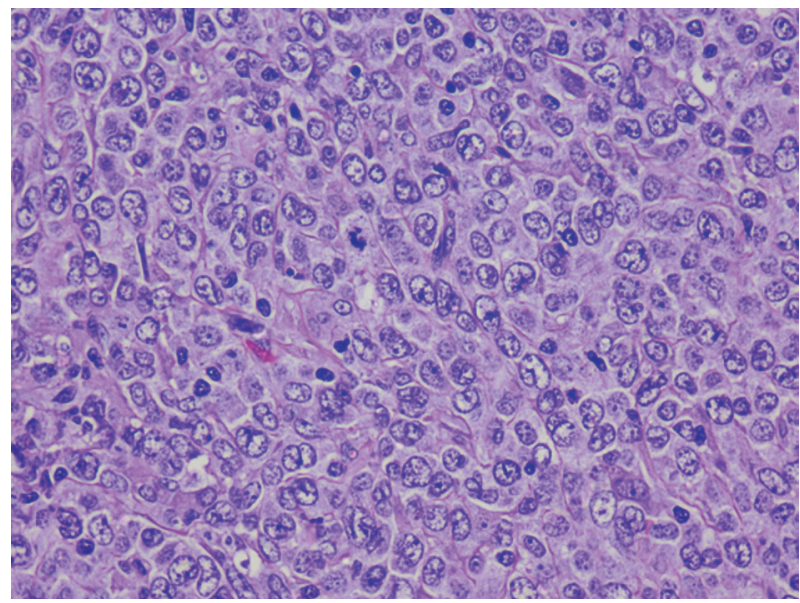

Figura 1. Na coloração hematoxilina e eosina, em maior aumento, nota-se a morfologia nuclear do tumor, com núcleos grandes, cromatina clara (sinal de alto metabolismo) e nucléolo evidente. $\mathrm{Na}$ imagem, há uma figura mitótica. Imagem aumentada em 400 vezes

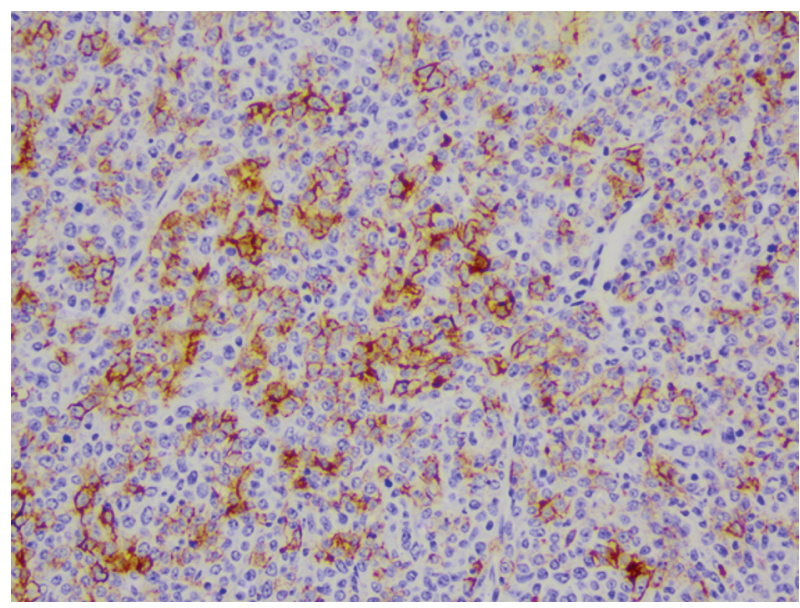

Figura 2. Neoplasia maligna positiva para CD20 multifocal. Imagem aumentada em 200 vezes

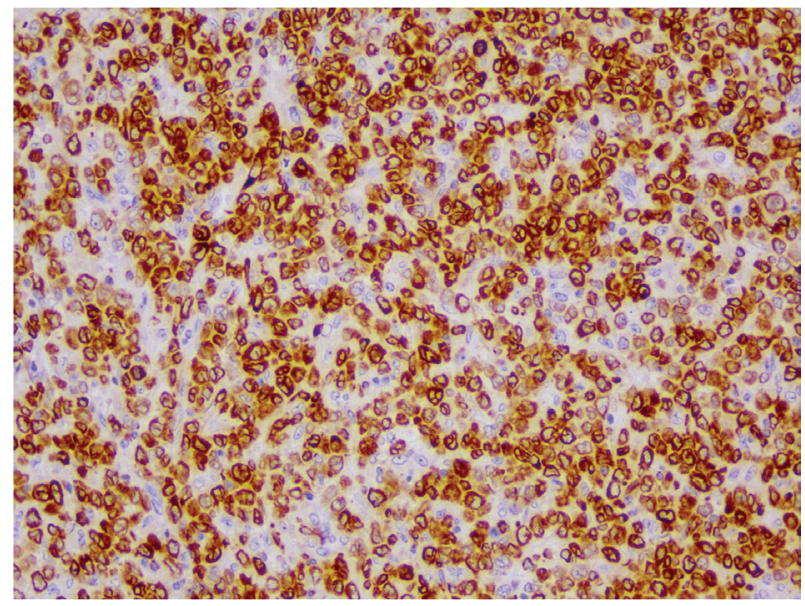

Figura 3. Reatividade difusa para BCL2. Imagem aumentada em 200 vezes

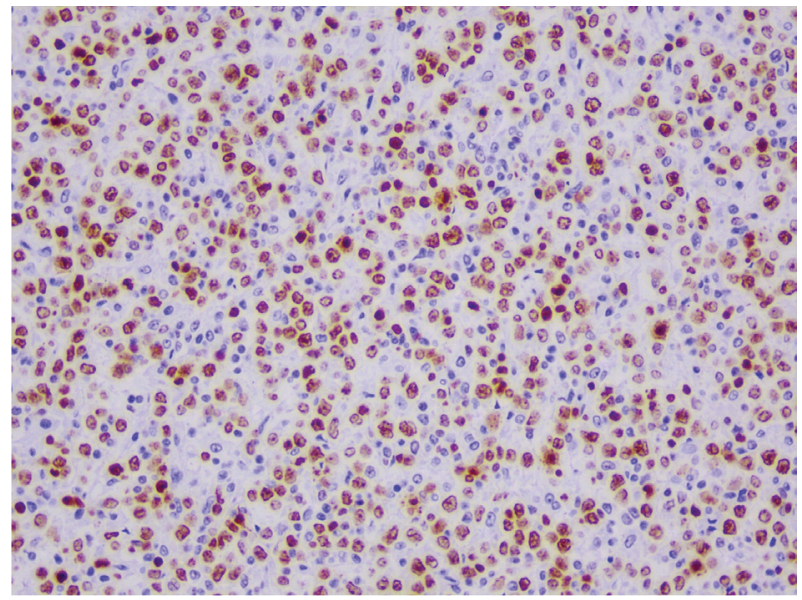

Figura 4. Alto índice proliferativo da neoplasia, em razão da alta porcentagem de núcleos de células malignas positivas para o Ki67. Imagem aumentada em 200 vezes

\section{DISCUSSÃO}

O paciente deste relato apresentou dor crônica em hipocôndrio esquerdo associada à sudorese noturna, com queixas perpetuando-se por mais de dois anos até que se chegasse a um diagnóstico.

O primeiro ponto importante a ser destacado é a inespecificidade dos exames laboratoriais, assim como dos exames de imagem, pois dificultaram o diagnóstico, evidenciando a necessidade de métodos diagnósticos mais específicos ${ }^{4}$. Neste caso, apesar do diagnóstico tardio, o paciente obteve remissão completa da neoplasia após a ressecção cirúrgica e quimioterapia.

O segundo principal ponto a ser discutido é a sintomatologia do paciente, que não condizia com o diagnóstico final de LNH de alto grau, fenótipo B, já que a primeira hipótese diagnóstica foi de um angiossarcoma esplênico. $\mathrm{O}$ paciente não relatava febre, perda ponderal e, tampouco, apresentava aumento de linfonodos. A queixa principal, neste caso, era uma dor abdominal persistente associada à sudorese noturna.

Tumores esplênicos primários são raros e os angiossarcomas representam uma prevalência menor ainda, de cerca de $1 \%$ dos sarcomas de tecidos moles, sendo essa porcentagem ainda menor em se tratando de tumor primário de baço ${ }^{1,2}$.

$\mathrm{Na}$ maioria dos casos de $\mathrm{LH}$, o quadro principal e inicial é o comprometimento de uma cadeia ou mais cadeias de linfonodos e, nos casos mais avançados, do baço e da medula óssea. Nos casos LNH, de uma maneira geral, além do comprometimento de linfonodos, podem existir manifestaçôes sistêmicas e presença de focos extranodais, em cerca de $25 \%$ dos casos. Contudo, em ambas as doenças, é raro que o tumor primário esteja localizado unicamente no baço. Além disso, estes representam um 
tipo de tumor que tem raríssima apresentação restrita a um único órgão, em virtude do seu alto potencial de disseminação $0^{3-5}$.

A primeira hipótese diagnóstica, após a entrevista clínica e a realização dos exames de imagem, foi de um angiossarcoma. Na cirurgia esplênica, o objetivo inicial era uma biópsia para exame histopatológico e, se necessário, estudo imuno-histoquímico. Contudo, por conta dos riscos e da dificuldade do acesso cirúrgico, optou-se por uma esplenectomia total. Após a esplenectomia e os estudos histopatológico e imuno-histoquímico, obteve-se o diagnóstico final. A análise histológica demonstrou morfologia tumoral, com presença de núcleos grandes, alta atividade metabólica em razáo da cromatina clara, assim como nucléolo mais evidente e, inclusive, mitoses (Figura 1).

Após o diagnóstico histopatológico de linfoma primário do baço, foi realizado o estudo imuno-histoquímico do material, para sua classificação $0^{6,7}$, com positividade para os marcadores CD20 em diversos focos, para o BCL2 e para o KI67, em cerca de $95 \%$ dos núcleos das células neoplásicas, com negatividade para CD3 e CD30. O diagnóstico definitivo foi compatível com LNH difuso de alto grau, com imunofenótipo B, primário do baço. Não havia sinais de comprometimento neoplásico nos tecidos adjacentes ao órgão retirado, estando a neoplasia restrita ao $\mathrm{baço}^{8}$, contrariando o caráter altamente infiltrativo do LNH de imunofenótipo $\mathrm{B}^{9}$. Assim, além de corroborar a definiçâo do diagnóstico preciso, o procedimento cirúrgico permitiu a retirada completa do tumor.

O paciente fez, em seguida, quatro ciclos de quimioterapia sob o esquema farmacológico R-CHOP. Desde 2002, esse esquema terapêutico vem sendo utilizado no tratamento de linfomas $\mathrm{LNH}$ de fenótipo B, trazendo aproximadamente $20 \%$ de melhora no prognóstico ${ }^{10}$. Hoje, o paciente apresenta-se em remissão completa e segue com acompanhamento em hospital de referência.

\section{CONCLUSÃO}

É de suma importância o reconhecimento do diagnóstico correto de neoplasias malignas raras como a relatada. Tanto a clínica quanto os exames complementares e de imagem, mesmo que fundamentais, podem não ajudar na definição diagnóstica. Recomenda-se sempre esse tipo de abordagem; ou seja, a realização de biópsia e/ou cirurgia para a retirada completa da peça cirúrgica comprometida e seu devido encaminhamento para o serviço de anatomopatologia. Sempre que necessário, o estudo histopatológico cuidadoso deve ser seguido do estudo imuno-histoquímico complementar adequado. Isso é muito importante principalmente em hospitais sem serviço de oncologia, como forma de realizar o diagnóstico precoce e correto, para que, dessa forma, consiga-se minimizar a morbimortalidade nesses pacientes oncológicos, evitando que o tratamento específico seja atrasado por causa de um diagnóstico tardio.

\section{CONTRIBUIÇÕES}

Gabrielle Ruthes Fragoso, Eduardo Pires dos Santos e Camila Aparecida Morais Marques contribuíram substancialmente na concepçáo e/ou planejamento do estudo; na obtenção, análise e/ou interpretação dos dados; na redação e revisão crítica. Renata Bernardini de Lima contribuiu substancialmente na concepçáo e/ ou planejamento do estudo; na obtenção, análise e/ou interpretação dos dados. Todos os autores aprovaram a versão final a ser publicada.

\section{DECLARAÇÃO DE CONFLITO DE INTERESSES}

Nada a declarar.

\section{FONTES DE FINANCIAMENTO}

Não há.

\section{REFERÊNCIAS}

1. Coppola S, Leva A, Pagni F, et al. Demanding diagnosis of splenic angiosarcoma as cause of delayed treatment of spontaneous splenic rupture: a case report and literature review. Case Rep Surg. 2017;2017:6256102. doi: https:// doi.org/10.1155/2017/6256102

2. Zhao Q, Dong A, Wang Y, et al. FDG PET/CT in primary splenic angiosarcoma with diffuse involvement of the spleen. Clin Nucl Med. 2017;42(10):815-7. doi: https://doi.org/10.1097/rlu.0000000000001805

3. Milito CB, Morais JC, Nucci M, et al. Classificação dos linfomas não-Hodgkin: estudo morfológico e imunoistoquímico de 145 casos. J Bras Patol Med Lab. 2002;38(4):315-24. doi: https://doi.org/10.1590/s167624442002000400011

4. Amin S, Findeis SK, Whiteley A, et al. An unusual presentation of an uncommon lymphoma, hepatosplenic T-cell lymphoma. Proc (Bayl Univ Med Cent). 2019;32(1):129-30. doi: https://doi.org/10.1080/0899 8280.2018.1509592

5. Myoteri D, Dellaportas D, Ayiomamitis G, et al. Erratum to "Primary angiosarcoma of the spleen: an oncological enigma." Case Rep Oncol Med. 2019;2019:5605401. doi: https://doi.org/10.1155/2019/5605401 
6. Werner B, Campos AC, Nadji M, et al. Uso prático da imuno-histoquímica em patologia cirúrgica. J Bras Patol Med Lab. 2005;41(5):353-64. doi: https://doi. org/10.1590/s1676-24442005000500011

7. Bascuas T, Moreno M, Mónaco A, et al. A novel nonHodgkin lymphoma murine model closer to the standard clinical scenario. J Transl Med. 2016;14(1):323. doi: https://doi.org/10.1186/s12967-016-1073-8

8. Martínez A, Martínez-Ramirez M, Martínez-Caballero $\mathrm{D}$, et al. Radioinmunoterapia en el linfoma no Hodgkin, posicionamiento, seguridad y eficacia de 90Y-ibritumomab. Experiencia y seguimiento a los 10 años. Rev Esp Med Nucl Imagen Mol. 2017;36(1):13-9. doi: https://doi.org/10.1016/j.remn.2016.05.004

9. Baena-Gómez MA, Matilla MM, Atienza AL, et al. Linfoma no Hodgkin: excelentes resultados a expensas de elevada toxicidad del tratamiento. An Pediatr. 2015;82(6):381-7. doi: https://doi.org/10.1016/j. anpedi.2014.09.005

10. Oliveira LC, Fardilha C, Louro M, et al. Palliative splenic irradiation for symptomatic splenomegaly in non-Hodgkin lymphoma. Ecancermedicalscience. 2018;12:887. doi: https://doi.org/10.3332/ ecancer.2018.887 